\title{
Pre-service Teachers' Knowledge of Identifying and Clearing Pupils' Misconceptions about Inverse and Composite Functions via Vignettes
}

\author{
Edgar John Sintema ${ }^{1 *}$, José M Marban ${ }^{1}$ \\ ${ }^{1}$ Universidad de Valladolid, SPAIN
}

Received 17 May 2020 - Accepted 27 October 2020

\begin{abstract}
The purpose of this study was to investigate pre-service teachers' knowledge of content and students vis-à-vis their ability to anticipate, identify and clear high school students' misconceptions about inverse and composite functions. To accomplish this goal a case study research design was used to examine one fourth year mathematics education pre-service teacher from one of Zambia's public universities. A case study strategy was preferred for this study because it enables the researcher to focus and have an in-depth investigation of an individual subject in a natural setting. As a data collection tool, the study used a questionnaire containing 7 vignettes comprising 4 inverse function vignettes and 3 composite function vignettes. Data were analyzed based on Ebert's framework for characterizing the level of proficiency of functions and graphs. Findings revealed that the pre-service teacher's level of proficiency of identifying and clearing students' misconceptions was mostly good. Results suggest that vignettes might be useful in mathematical pedagogical courses in teacher education.
\end{abstract}

Keywords: pre-service teachers' KCS, pupils' misconceptions, inverse and composite functions, vignettes

\section{INTRODUCTION}

Effective teaching occurs when a teacher possesses strong knowledge of mathematics content and that of students' entry characteristics to learning a particular topic. This study showcased the use of a novel approach of using vignettes to study teachers' knowledge of students' misconceptions on inverse and composite functions.

The purpose of this study was to better understand the level of pre-service teachers' mathematical pedagogical content knowledge related to their ability to identify and clear students' misconceptions involving inverse and composite functions. Teachers' knowledge of students' misconceptions is important because it helps eradicate problems that students may have which are caused by wrong conceptions about mathematics. Thus, teachers would teach with confidence if they are able to help students in all areas where they have misunderstanding of concepts. This study is crucial to teacher education providers in the sense that it will provide valuable information about areas of the function concept where pre-service teachers have difficulties. This can help in finding solutions to these problems.

\section{Using Vignettes to Study Pre-service Teachers' MPCK}

Vignettes have been a useful tool for measuring subject matter knowledge and understanding instructional strategies of pre- and in-service mathematics teachers (Campbell, 1996; Ebert, 1993; Graven, 2005; Jeffries \& Maeder, 2005; Karahasan, 2010; Knievel et al., 2015; Moomaw, 2011; Stecher et al., 2006; Tasar, 2006).

In a study to promote good math and science education, Campbell (1996) posited that vignettes offer real life value to understanding instructional strategies because they act as a foundation for discussions aimed at finding solutions of various issues related to mathematics and science pedagogy. Vignettes have proved effective in experimenting and building on ideas in the wake of improving practice. 


\section{Contribution to the literature}

- This study emphasizes the use of vignettes in examining pre-service teachers' mathematical pedagogical content knowledge.

- The study shares new findings about mathematics pre-service teachers' knowledge of misconceptions related to inverse and composite functions.

- The study contributes literature about pre-service teachers' subject matter knowledge of secondary school concepts involving inverse and composite functions.

In another study aimed at assessing pre-service secondary teachers' pedagogical content knowledge about functions and graphs, Ebert (1993) used vignettes as a springboard for an in-depth interview about their PCK of functions and graphs. Results of the study revealed that majority of participants exhibited good subject matter knowledge of functions and graphs. The number of teachers who demonstrated inadequate knowledge about subject matter were equal to those who possessed strong knowledge. As regards PCK, majority of teachers possessed good level of PCK of functions and graphs. Graven (2005) used vignettes to develop an inservice education and training program for teachers to improve their professional development skills.

In a study aimed at building and assessing teacher understanding of instructional strategies, Jeffries and Maeder (2005) found a significant correlation between vignettes and traditional assessment methods. They also posited that vignettes were predictive of end of course performance and were a good way of learning. They further proposed continuous development and use of vignettes. To this effect, Knievel et al., (2015) developed video vignettes for measuring primary teachers' competencies in and for teaching mathematics.

A book focused on teaching mathematics in early childhood (Moomaw, 2011) included vignettes to model mathematics concepts. It was argued in this book that early exposure to mathematical concepts increased possibilities of future self-interest and strength in the subject. Children who are introduced to mathematics early in their lives have the potential to excel in the subject in more advanced levels of education. Stecher et al. (2006) used vignettes to measure fourth-grade teachers' instructional practices in mathematics. Findings revealed that vignettes are a unique tool in measuring teachers' classroom instruction practices in the sense that they measure important aspects of reformoriented teaching which other measurement tools fail to capture. They reiterated that vignettes were essential tools in studying teachers' instructional practices and can be complemented by interviews for an insightful understanding.

Tasar (2006) used vignettes to examine middle school science teachers' scientific knowledge. Findings revealed the usefulness of vignettes in investigating teacher knowledge. It was also revealed that teachers showed a positive development of scientific knowledge.
The foregoing studies demonstrate the importance of using vignettes to examine pre- and in-service teachers' Mathematical Pedagogical Content Knowledge (MPCK). While assessing MPCK, vignettes have the advantage of indirectly revealing teachers' subject matter knowledge. Thus, this characteristic influenced the researchers to adopt vignettes for this study.

\section{Pre-service Teachers' Knowledge of Inverse and Composite Function}

There is sufficient evidence in literature which shows that prior research about the concept of a function focused on pre-service teachers' knowledge of inverse and composite functions (Even, 1992; Karahasan, 2010; Kontorovich, 2017; Paoletti, 2020; Wasserman, 2017).

Pre-service teachers have difficulties with function concepts. Research shows that they have weak knowledge of both inverse and composite functions (Karahasan, 2010). They have difficulties with correct usage of mathematical symbols related to composite functions and in some cases confused the composition of functions with ordinary multiplication (Kontorovich, 2017). They also exhibited insufficient knowledge of the meaning of inverse functions (Paoletti, 2020) which could mean that they were not fully prepared to teach secondary school concepts involving inverse functions.

Their inability to demonstrate mathematically strong understanding of inverse functions coupled with failure to recognize patterns and connections involving inverse functions (Even, 1992; Wasserman, 2017) implies that there is serious need to pay attention to their difficulties during teacher training and this could affect their ability to teach because effective MPCK could come about when a teacher has a strong subject matter knowledge background. This is consistent with the views of Weber et al., (2020) who found that teachers better respond to pedagogical issues regarding inverse function concepts that they are likely to encounter in future. Even their understanding and contextual interpretation of the polysemous symbol [superscript (-1)] was found to be a big problem among them (Kontorovich, 2017; Lim, 2016).

\section{METHODOLOGY}

This study followed a qualitative case study research design. This research strategy was chosen because we wanted to have in-depth understanding of the teacher's 
knowledge of students' conceptions as well as misconceptions of inverse and composite functions. Case studies are suitable for studies that seek to investigate an individual's knowledge characteristics about a particular topic.

\section{Participants}

One pre-service teacher from a public university in Zambia participated in this study. The pre-service teacher was in his final year of study at the time of his participation in this study. He had already covered mathematics content suitable for him to participate in the study and at the time of data collection for the study he was doing his teaching practice at one of the public schools in Eastern Zambia.

\section{Instruments}

Data for this study were collected using 7 vignettes. Of the 7 vignettes, 4 were about inverse functions and 3 about composite functions (see Appendix A). All the vignettes were adapted from Karahasan (2010). The vignettes fit the Zambian context and the depth of content covered is equivalent to that of the Zambian senior secondary school syllabus. The instrument was validated following a rigorous validation procedure to ensure that it perfectly reflected the Zambian context to the participant.

\section{Validation of the vignettes}

Evaluation of the face validity of the instrument where this vignettes (See Appendix A) came from was accomplished based on the level of agreement of 10 experts. The instrument was composed of 12 vignettes designed to measure teachers' MPCK of the function concept. Based on the comments of experts and $75 \%$ level of agreement of experts on the suitability of the vignettes to the Zambian context, one vignette was removed from the instrument because it was below the $75 \%$ level of agreement (Ohanian, 1990). The remaining 11 vignettes which met the agreement threshold formed the pre-final version of the instrument. The vignettes in the pre-final version of the instrument were not edited in any way because the experts recommended that they be used in the state in which they were. The pre-final version was then subjected to content validity evaluation.

The instrument was then evaluated for its content validity. This process involved assessment of each vignette for its clarity, relevance and coherence on a 4point ordinal scale: 1 = does not meet the criteria, $2=$ Low level, 3 = Moderate level and $4=$ High level. This was to ensure that the wording of the vignettes was clearly done without any ambiguities and each vignette was relevant to measuring MPCK. The entire instrument from which this vignette was picked was also evaluated for its sufficiency to thoroughly measure MPCK based on the same scale as other constructs. At this stage only vignettes that were rated 3 or 4 were retained in the final version. Following this criteria only 8 vignettes formed the final version of the instrument. The final version had a scale content validity index (S-CVI) of 0.90 and item content validity index (I-CVI) of 0.80 . These validity indices implied that the instrument was valid for use in this study.

\section{Data Analysis}

Data were analyzed based on Ebert's framework (1993) consisting of three levels: Level $0=$ inadequate, Level $1=$ Good and Level 2 = strong. The framework and the categorization of levels of proficiency are presented in Table 1 (see Appendix B).

Concerning their Knowledge of Content and Students (KCS), pre-service teachers' knowledge is inadequate at level 0 . At this level pre-service teachers have difficulties in identifying students' emerging errors, difficulties and misconceptions about the function concept. They find it difficult to diagnose students' emerging errors and misconceptions about the function concept and usually when choosing examples, they are not able to pay attention to aspects of the examples that would excite, motivate and interest students. They are also not able to mind the level of difficulty of the tasks that they assign to their students. Similarly, at this level pre-service teacher are not able to pay attention to students' use of mathematical language and symbols related to functions.

At level 1, pre-service teachers have good knowledge of the function concept and begin to identify students' emerging errors, difficulties and misconceptions about the function concept, and when choosing examples they partially pay attention to aspects of examples that would excite, motivate and interest their students. At this level pre-service teachers are partially mindful of the level of difficulty of the tasks that they assign to students and are partially able to pay attention to students' use of mathematical language and symbols related to functions.

At level 2 pre-service teachers' knowledge of functions content and students is considered to be strong. At this level they are able to easily identify and diagnose students' emerging errors, difficulties and misconceptions about the function concept. They also demonstrate their ability to easily diagnose students' emerging errors and misconceptions about the function concept and pay attention to aspects of examples that would excite, motivate and interest their students when choosing examples during lesson preparation. Preservice teachers at this level are mindful of the level of difficulty of the tasks that they assign to students and pay attention to students' use of mathematical language and symbols related to functions. A summary of the characterization of pre-service teachers' knowledge of 


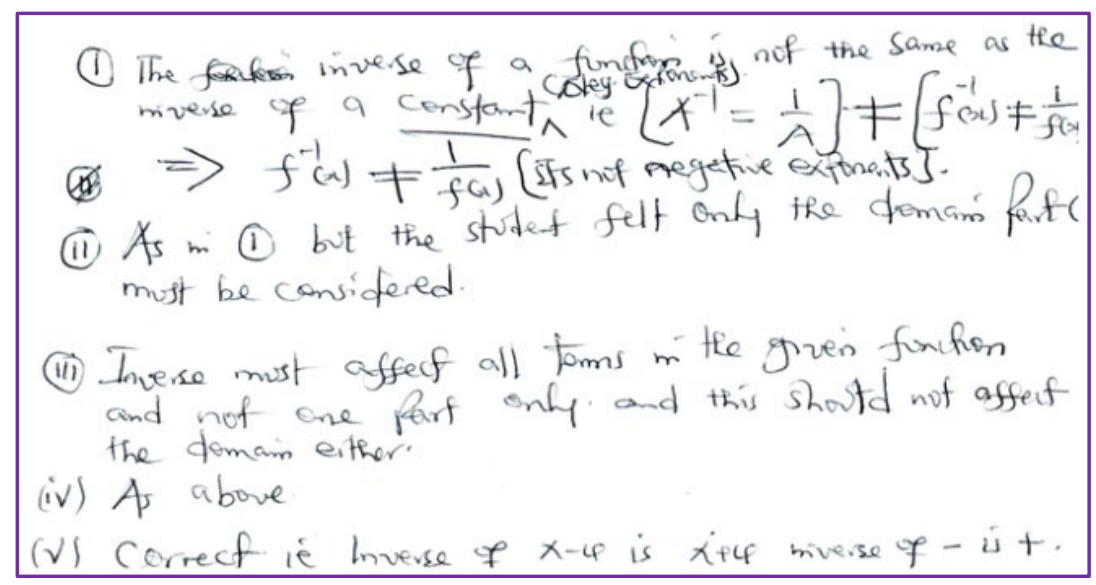

Figure 1. Excerpt of Teacher $X^{\prime}$ s response to vignette 1

functions content and students is shown in Table 1 (Appendix B).

\section{RESULTS}

This section presents results of responses to vignettes from one mathematics pre-service secondary teacher. The first part of the results showcases the teacher's responses to vignettes related to inverse functions whereas the second highlights responses to vignettes related to composite functions. Presenting results in this way makes it easy to know aspects of KCS of functions where the teacher had more knowledge.

\section{Vignettes Assessing Pre-service Teachers' KCS of Inverse Functions}

These vignettes were aimed at assessing pre-service teachers' ability to identify and clear pupils' misconceptions about inverse functions. The vignettes partly expose teachers' understanding subject matter related to the function concept. This is because ability to clear misconception is dependent on teachers' knowledge of subject matter. For the purpose of good presentation of results, the pre-service teacher who participated in this study was named Teacher X.

\section{Vignette 1}

This vignette was centered on teacher's ability to understand inverse function notation and how it caused misconceptions by conflicting with concepts in arithmetic (multiplicative inverse) and negative exponents when dealing with indices and exponential functions. The teacher demonstrated superior understanding of inverse function notation and explained how it differed from multiplicative inverse in arithmetic. This helped the teacher to spot defects in the reasoning of the students in the solutions presented. The teacher was equally able to recognize the correct answer. Considering the clarity of concepts in the teacher's explanations, his response to this vignette was rated level 2 (Figure 1).

\section{Vignette 2}

This vignette was meant to assess the teacher's ability to demonstrate knowledge of existence of inverse functions and to highlight conditions under which a function can exist. The teacher explained that for a function to have an inverse it must be a one-to-one function. He used the concepts of domain and range to emphasize this point. However, he seemed to confuse the horizontal line test for testing that a function is oneto-one with a vertical line test for testing whether a particular graph is a function. By using a graph (different representation) to explain existence of inverse of a function the teacher demonstrated high order understanding of the inverse function concept and conditions related to its existence. Thus, his explanations were rated 1 (Figure 2).

\section{Vignette 3}

This vignette was aimed at assessing the teacher's understanding of the inverse function definition and how he can explain it to make his students comprehend it. It also sought to assess the teacher's ability to understand and employ analogies in his teaching. The teacher found the given analogy to be appropriate for use in defining the inverse of a function and stated that it would not cause misunderstanding among the students. However, the teacher could not give his own real life example of how he would emphasize the definition of the inverse function. He did not also elaborate how he would handle the confusion arising from his students' failure to comprehend a formal definition of the inverse function. That showed limited understand regards teacher's use or real life situations to define function concepts. Thus, his response to this vignette was rated level 0 (Figure 3). 


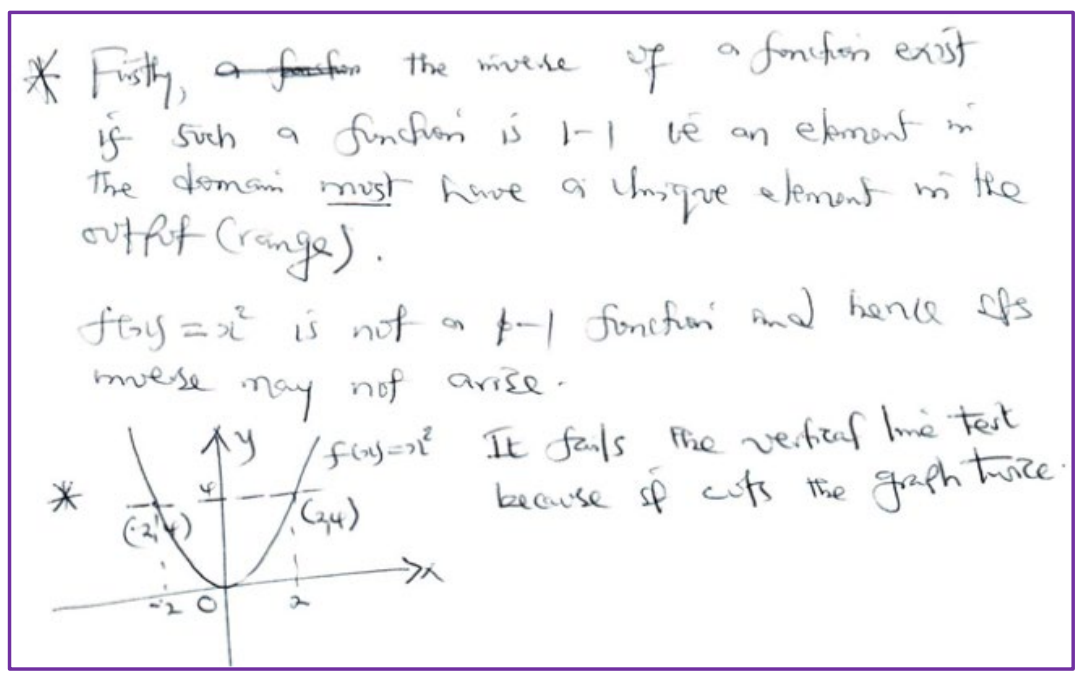

Figure 2. Excerpt of Teacher X's response to vignette 2

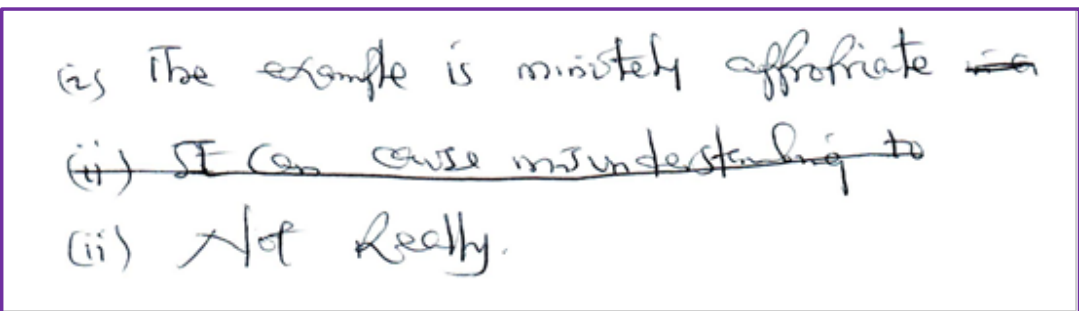

Figure 3. Excerpt of Teacher X's response to vignette 3

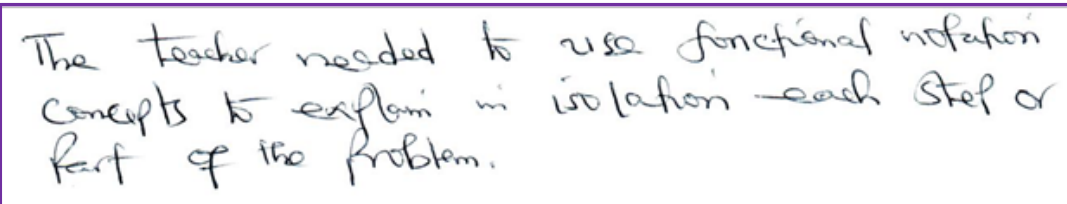

Figure 4. Excerpt from Teacher X's response to vignette 4

\section{Vignette 4}

In this vignette, the teacher was expected to notice that two concepts were involved in the solution by the student. Thus, the main purpose of this vignette was to see if the teacher would recognize that concepts related to inverse functions were combined to concepts related to composite functions. The teacher, however, could not recognize this and concentrated on the use of "notation in each step" of the solution. The teacher did not demonstrate understanding of this vignette. Hence, his explanation was rated level 0 (Figure 4).

\section{Vignettes Assessing Pre-service Teachers' KCS of Composite Functions}

These vignettes showcased pre-service teachers' ability to identify and clear pupils' misconception about composite functions. By identification and clearance of pupils' misconceptions the teacher was also exhibiting his subject matter knowledge of the function concept.

\section{Vignette 5}

This vignette exemplified the definition of a composite function using a real life situation. The vignette was calling on the teacher's understanding of the definition(s) and how a teacher can move between theoretical to practical or real life examples in explaining a concept (Figure 5).

The teacher demonstrated understanding of the definition of composite functions by stating that the given real life example was appropriate in providing an alternative explanation regarding the definition. The teacher was also able to breakdown parts of the given analogy and showed how they combined to fit the definition of composite functions. The real life example given by the teacher was a true reflection of a composite function. It showed good understanding of using analogies to explain mathematical concepts and epitomized the importance analogies play in teaching function concepts. This response to vignette 5 was rated level 1. 


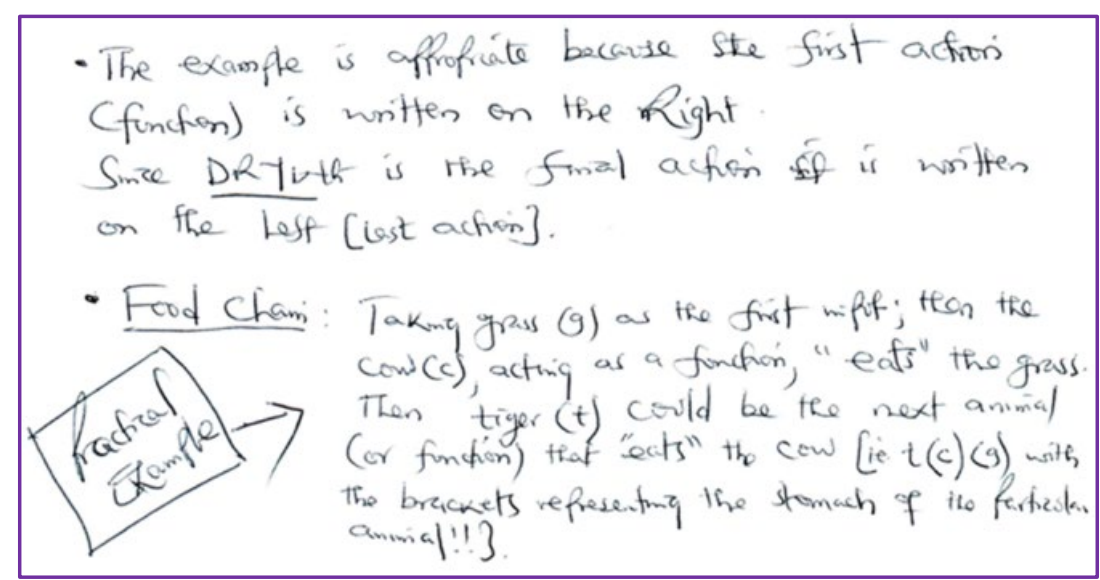

Figure 5. Excerpt from Teacher $X^{\prime}$ s response to vignette 5

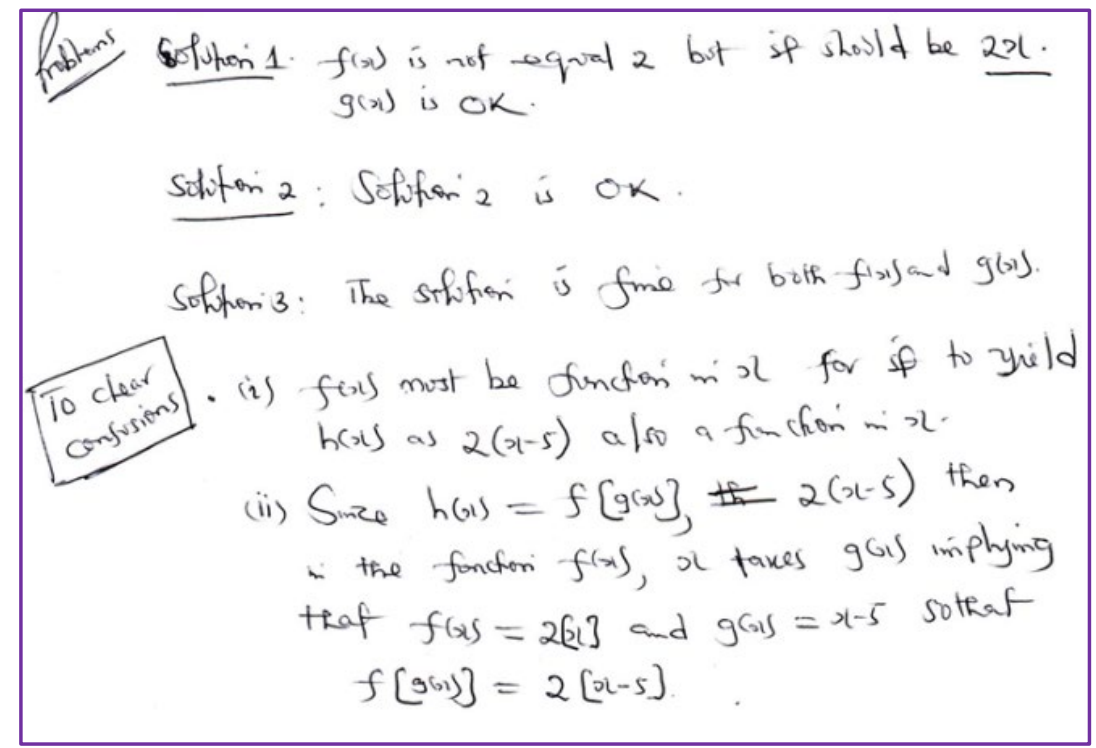

Figure 6. Excerpt from Teacher X's response to vignette 6

\section{Vignette 6}

This vignette was basically testing the understanding of composite function definition and how composite functions differ from ordinary functions. The vignette required the students to also distinguish the composite function $f[g(\mathrm{x})]$ from ordinary multiplication of algebraic terms $f(\mathrm{x}) \cdot g(\mathrm{x})$ (Figure 6).

The teacher correctly states that $f(x)=2$ in the first response is incorrect whereas $g(x)=(x-5)$ is correct. The teacher also explicitly stated that the second and third responses were correct. The teacher did refer to the definition of composite functions and made no attempt in identifying the misconception the first student exhibited when he assumed that $h(x)$ was equal to $f(x) \cdot g(x)$. He rather relied on the understanding that $f(x)$ needed to be a function of $\mathrm{x}$ just like $g(\mathrm{x})$ was a function of $x$. In his attempt to clear the confusion, the teacher relied on the definition of composite functions without explicitly demonstrating how he understood the definition and how it applied to the situation. The teacher did not use different representation of functions to clear the confusion in class and did not use other examples either. Since the teacher was able to identify the error in the first response and correctly stated that $f(x)$ was supposed to be $2 x$ but did not explicitly demonstrated how the confusion was largely related to lack of understanding of the definition of composite functions and did not even use or mention different representations, and how to use them to understand the definition, the response to vignette 6 was rated 0 .

\section{Vignette 7}

This vignette was meant to show the importance of the order in which the functions were taken when simplifying composite functions. It was trying to demonstrate that commutative law in arithmetic operations was not applicable to operations on composite functions. When combining two or more functions order in which the composition is written must be respected (Figure 7). 


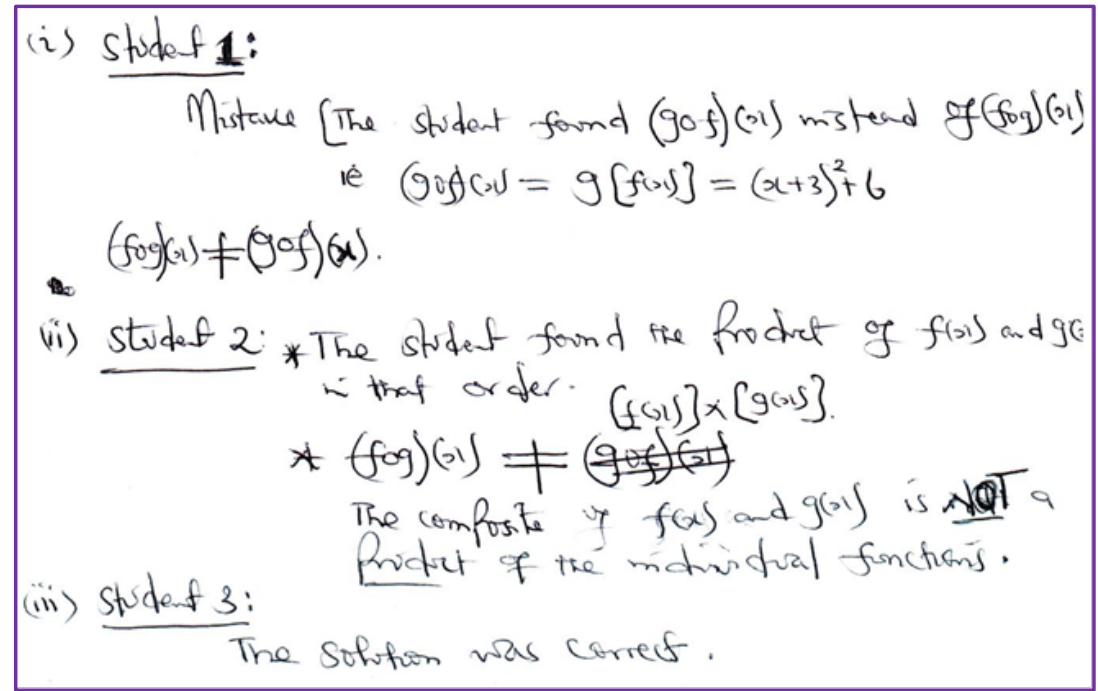

Figure 7. Excerpt from Teacher X's response to vignette 7

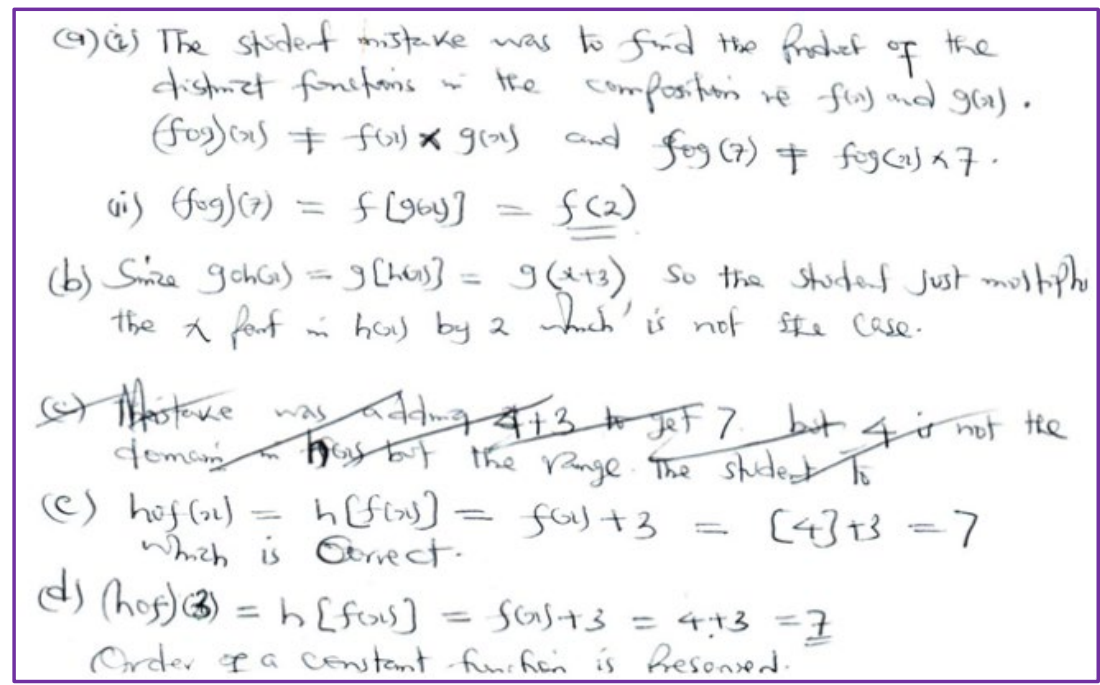

Figure 8. Excerpt from Teacher X's response to vignette 8

Teacher $\mathrm{X}$ was able to identify mistakes made by the first and second students in their work. In the answer given by the first student, teacher $\mathrm{X}$ was able to highlight that order of operations when applied to composite functions was important. Though not stated explicitly, Teacher $\mathrm{X}$ demonstrated that the commutative law of arithmetic was not applicable to operations on functions. He showed it by stating that $f \circ g(x)$ was not equal to gof $(x)$. In the answer given by the second student, Teacher X categorically stated that the "composition of $f(x)$ and $g(x)$ is NOT a product of the individual functions". In this vignette the teacher showed good understanding of the meaning of the composition of functions and how it differs from a product of two functions. He also showed how order was important when combining two functions. Though he did not explain how he would resolve students' misconceptions that would arise in the vignette he demonstrated good conceptual understanding. Thus, the response was rated level 1.

\section{Vignette 8}

This vignette presented a situation where one of the functions involved in the composition was a constant function. In such situations misconceptions occur when students resort to finding products of given functions as their composition. This vignette, therefore, was trying to bring out the teacher's ability to recognize possible errors and misconceptions that would arise when finding the composition of two functions where one was a constant function (Figure 8).

The teacher demonstrated very good understanding of the demands of this vignette. He clearly stated in his explanation of the mistake made in the first answer that composition of functions did not mean the product of individual functions by arguing that $(\mathrm{fog})(\mathrm{x}) \neq \mathrm{f}(\mathrm{x}) \times \mathrm{g}(\mathrm{x})$ and $(\mathrm{fog})(\mathrm{x}) \neq(\mathrm{fog})(\mathrm{x}) \times 7$. Similarly the teacher identified the error committed in the solution for the second question by stating that $(\mathrm{goh})(\mathrm{x})=\mathrm{g}[\mathrm{h}(\mathrm{x})]$ which does not imply multiplication. However, the student multiplied 
the functions $\mathrm{g}(\mathrm{x})$ and $\mathrm{h}(\mathrm{x})$. The teacher nods the answer provided for part (c) and corrects the mistake made in the solution for part (d) by giving an explanation. Thus, it was seen in the teacher's responses that he demonstrated his ability to correctly identify student mistakes and providing correct solutions but he did not attempt to explain in detail how to clear the confusion to avoid reoccurrence of similar mistakes. This meant that the teacher still had difficulties in providing conceptual explanations and justifications that would help his students avoid making similar mistakes. Thus, his solutions to this vignette were rated level 1.

\section{DISCUSSION AND CONCLUSION}

The purpose of this study was to examine and understand pre-service teachers' knowledge of identifying and clearing students' misconceptions about inverse and composite functions. This was accomplished using vignettes related to the two aspects of the function concept.

Concerning teacher knowledge of identifying and clearing pupils' misconceptions about inverse functions, the overall picture suggests that the teacher does not have a desirable level of knowledge across all vignettes. The teacher exhibited strong knowledge of understanding and interpreting the polysemous symbol (of superscript - 1 ) used to denote inverse functions (1 out of 4 vignettes). The teacher was able to identify the source of students' misconception and provided a valid explanation about how to clear this misconception. This finding was not consistent with the findings of Kontorovich (2017), Lim (2016) and Weber et al., (2020) whose results indicated that interpretation of the polysemous symbol was particularly a big problem with pre-service mathematics teachers.

The pre-service teacher in this study also demonstrated that he had good knowledge of determining of whether a given function had an inverse or not ( 1 out 4 vignettes). By stating that a given function would be invertible if it was a one-to-one function the teacher showed that he was aware of the conditions under which inverse functions existed.

However, the teacher possessed inadequate knowledge in 2 out of 4 vignettes. The teacher demonstrated inadequate knowledge of the definition of inverse function and he was unable to use any real life example or an analogy to make the students understand. Failure to define and show patterns and relationships between concepts governing inverse functions likely to affect the teacher's ability to clear misconceptions and would negatively affect the teacher's ability to effectively teach the concept. This finding is consistent with many studies that found pre-service teachers with insufficient knowledge of aspects inverse functions (Even, 1992; Wasserman, 2017).
Concerning composite functions the teacher exhibited a good level of knowledge of pupils' misconceptions in majority of the vignettes ( 3 out of 4 vignettes). In these vignettes the teacher was able to identify the source of the misconceptions and provided good explanations of how to clear confusion among students. However, in one vignette (Figure 6) the teacher was unable to convincingly offer a mathematically valid explanation of clearing a misconception.

In conclusion, we argue that vignettes offer a uniquely good method for investigating pre-service teachers' knowledge of students' misconceptions because of their tendency to present a real classroom situation that the teacher has to deal with. In as much as the vignettes give us the mathematical pedagogical content knowledge of a teacher, it also confirms the subject matter difficulties and strengths of the teacher. The teacher's ability in the study to identify and offer explanations aimed at clearing misconceptions was dependent on the level of his subject matter knowledge.

We recommend that universities involved in providing mathematics teacher education in Zambia should use much of vignettes in assignments for preservice teachers to strengthen their knowledge of students' misconceptions and to acquaint them with the kind of mathematics concepts they will encounter at secondary school.

Considering that in recent times studies in mathematics education rarely use vignettes in studying teacher knowledge, this study would re-ignite the interest in using vignettes because these tools provide a unique opportunity for a researcher who is investigating pedagogical content knowledge to indirectly have insight about participants' subject matter knowledge. Vignettes can also be effectively used to study pre- and in-service teachers' responses to pedagogical problems about mathematics subject matter.

\section{REFERENCES}

Campbell, P. B. (1996). How Would I Handle That? Using Vignettes to Promote Good Math and Science Education. Washington, DC: American Association for the Advancement of Science.

Ebert, C. L. (1993). An assessment of prospective secondary teachers' pedagogical content knowledge about functions and graphs. Presented at the annual meeting of the American Educational Research Association, Atlanta, April 1993.

Even, R. (1992). The inverse function: Prospective teachers' use of "undoing". International Journal of Mathematical Education in Science and Technology, 23(4), 557-562. https:// doi.org/10.1080/0020739X. 1992.10715689

Graven, M. (2005). Mathematics teacher retention and the role of Identity: Sam's story. Pythagoras, 
2005(61), 2-10. https://doi.org/10.4102/ pythagoras.v0i61.116

Jeffries, C., \& Maeder, D. W. (2005). Using vignettes to build and assess teacher understanding of instructional strategies. Professional Educator, 27, 1728.

Karahasan, B. (2010). Pre-service secondary mathematics teachers' pedagogical content knowledge of composite and inverse functions (Doctoral Dissertation), Middle East Technical University, Turkey.

Knievel, I., Lindmeier, A. M., \& Heinze, A. (2015). Beyond knowledge: Measuring primary teachers' subject-specific competences in and for teaching mathematics with items based on video vignettes. International Journal of Science and Mathematics Education, 13(2), 309-329. https:/ / doi.org/10.1007/ s10763-014-9608-Z

Kontorovich, I. (2017). Students' confusions with reciprocal and inverse functions. International Journal of Mathematical Education in Science and Technology, 48(2), 278-284. https://doi.org/10.1080 /0020739X.2016.1223361

Lim, K. H. (2016). Fostering algebraic understanding through math magic. Mathematics Teacher, 110(2), 110-118.

https:/ / doi.org/10.5951/mathteacher.110.2.0110

Moomaw, S. (2011). Teaching Mathematics in Early Childhood. Brookes Publishing Company.

Ohanian, R. (1990). Construction and validation of a measure celebrity endorsers' perceived expertise, trustworthiness, and attractiveness. Journal of advertising, 19(3), 39-52. https://doi.org/10.1080/ 00913367.1990 .10673191

Paoletti, T. (2020). Reasoning about relationships between quantities to reorganize inverse function meanings: The case of Arya. The Journal of Mathematical Behavior, 57, 100741. https://doi.org/ 10.1016/j.jmathb.2019.100741

Stecher, B., Le, V. N., Hamilton, L., Ryan, G., Robyn, A., \& Lockwood, J. R. (2006). Using structured classroom vignettes to measure instructional practices in mathematics. Educational evaluation and policy analysis, 28(2), 101-130. https://doi.org/ 10.3102/01623737028002101

Tasar, M. F. (2006). Probing Preservice Teachers' Understandings of Scientific Knowledge by Using a Vignette in Conjunction with A Paper and Pencil Test. Eurasia Journal of Mathematics, Science and Technology Education, 2(1), 53-70. https://doi.org/ 10.12973 / ejmste/ 75438

Wasserman, N. H. (2017). Making sence of abstract algebra: Exploring secondary teachers' understanding of inverse functions in relation to its group structure. International Journal of Mathematical Education in Science and Technology, 19(3), 181-201. https:/ / doi.org/10.1080/10986065.2017.1328635

Weber, K., Mejía-Ramos, J. P., Fukawa-Connelly, T., \& Wasserman, N. (2020). Connecting the learning of advanced mathematics with the teaching of secondary mathematics: Inverse functions, domain restrictions, and the arcsine function. The Journal of Mathematical Behavior, 57, 100752. https:/ / doi.org/ 10.1016/j.jmathb.2019.100752 


\section{APPENDIX A}

The vignettes in this section were adapted from Karahasan (2010).

\section{Vignette 1}

You have been discussing the concept of inverse functions in class. You pose the following question in class.

Determine the inverse $\left[\mathrm{f}^{-1}(\mathrm{x})\right]$ of a function $\mathrm{f}(\mathrm{x})=\mathrm{x}-4$.

Five different solutions come out from the class.

(i) $f^{-1}(\mathrm{x})=\frac{1}{\mathrm{x}-4}$

(ii) $f^{-1}(\mathrm{x})=\frac{1}{\mathrm{x}}-4$

(iii) $f^{-1}(\mathrm{x})=-\mathrm{x}-4$

(iv) $f^{-1}(\mathrm{x})=-\mathrm{x}+4$

(v) $f^{-1}(\mathrm{x})=\mathrm{x}+4$

The different answers reveal that the class is confused.

What is the problem in each solution (if there exists)?

Explain how you would respond to these comments and clear up confusion during a class.

\section{Vignette 2}

A student said the inverse of the function $x^{2}=\sqrt{x}$.

Is the student right? If you think that the student is correct explain why?

If you think the student is incorrect explain where the error lies and how you would respond to these comments and clear up confusion in lass.

\section{Vignette 3}

A teacher gave the definition of the inverse function and explained it on the board to his/her students. However, some of the students stated that they did not understand it completely. The teacher then gave the following example to the students.

If you think of a school bus as a function which takes you from home to school in the morning, then the school bus that takes you back from school to home is the inverse of the first function.

* What do you think of this example?

* Can the example cause students to misunderstand any points in the definition?

* If exists, please explain these points. If you were to explain the inverse function by using a real life example, what will be your example?

* Explain how you will use it in class.

\section{Vignette 4}

You have been discussing the concept of inverse functions in class. You pose the following problem in class.

If $f(2 x+1)=2 x-1$, find $f(3 x)$ and $f(x)$ and explain the steps of your solution.

The students solved the question correctly as follows:

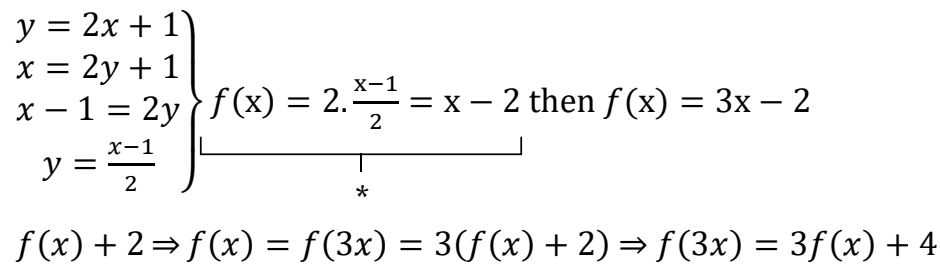

After the solution made, teacher wants from the student to explain what she did in the step indicated by *. She said "I have to get $f(x)$ so that I could calculate $f(3 x)$.

For getting $\mathrm{f}(\mathrm{x})$ I made the necessary calculation as you did in our previous examples".

Further, teacher wants from the students to explain what she did in the $f(x)+2=x$ step. She said that "we have to single out $x$ from the equation as you did in our previous examples". However, she couldn't explain what she did.

What should teacher do to make his/her students understand the case? 


\section{Vignette 5}

A teacher gave the definition of a composite function and explained it on the board to his/her students. However, some of his/her students stated that they did not understand it completely.

Then the teacher gave the following example to the students.

In order to clean and dry your clothes in a laundry we use two machines, washing machine and Dryer, respectively. Dry \& wash(clothes).

$\operatorname{Dry}[$ Wash $($ clothes $)]=$ Dry[cleaned and wet clothes $]=$ dried and cleaned clothes. Combination of these machines works can be considered as a composition of functions.

What do you think of this example? Can this example cause to misunderstand any points in the definition? If exists, please explain these points. If you were to explain the composite function by using a real life example, what will be your example? Explain how you will use it in class.

\section{Vignette 6}

This vignette was basically testing the understanding of composite function definition and how composite functions differ from ordinary functions. The vignette required the students to also distinguish the composite function $f[g(\mathrm{x})]$ from ordinary multiplication of algebraic terms $f(\mathrm{x}) \cdot g(\mathrm{x})$.

You have been discussing the concept of composite functions in your grade 10 class. You pose the following problem in class.

Let $h(x)=f[g(x)]$ and determine $f(x)$ and $g(x)$ if $h(x)=2(x-5)$.

One student suggests that " $g(x)=x-5$ and $f(x)=2$ "

Another student interrupts "no $f(x)$ must be equal to $2 x$ if $g(x)=x-5$ "

A third student remarks "well I think $g(x)=x-5$ and $f(x)=2 x$ "

The class seems confused.

What is the problem in each solution (if there is any)? Explain how you would respond to these comments and clear up confusion during class.

\section{Vignette 7}

This vignette was meant to show the importance of the order in which the functions were taken when simplifying composite functions. It was trying to demonstrate that commutative law in arithmetic operations was not applicable to operations on composite functions. When combining two or more functions order in which the composition is written must be respected.

You have been discussing the concept of composite functions in class. You pose the following problem.

Determine the composite function $(f \circ g)(x)$ if $f(x)=x+3$ and $g(x)=x^{2}+6$.

One student answers the problem as " $(\mathrm{fog})(\mathrm{x})=(\mathrm{x}+3)^{2}+6$ ".

Another student answered the problem as " $(\mathrm{fog})(\mathrm{x})=(\mathrm{x}+3)\left(\mathrm{x}^{2}+6\right)^{\prime \prime}$.

A third student answered it as " $(\mathrm{fog})(\mathrm{x})=\mathrm{x}^{2}+9^{\prime \prime}$.

For each of the incorrect solutions;

What is the source of the mistake? (show and explain how they may have found the solution).

Explain how you would respond to these comments and clear up confusion during a class.

\section{Vignette 8}

This vignette presented a situation where one of the functions involved in the composition was a constant function. In such situations misconceptions occur when students resort to finding products of given functions as their composition. This vignette, therefore, was trying to bring out the teacher's ability to recognize possible errors and misconceptions that would arise when finding the composition of two functions where one was a constant function.

A student asked the following question.

Let $f(x)=4, g(x)=2$ and $h(x)=x+3$. Evaluate the following

a. $(f \circ g)(7)$

b. $(g \circ h)(x)$

c. $(h \circ f)(x)$

d. $($ hof $)(3)$ 
Student's answer is the following:

$$
\begin{aligned}
& \text { a. } f(x)=4 \text { and } g(x)=2, \text { then }(f \circ g)=(4.2)=8,(f \circ g)(7)=56 \\
& \text { b. }(g \circ h)(x)=2 x+3 \\
& \text { c. }(\text { hof })(x)=7 \\
& \text { d. }(\text { hof })(5)=32
\end{aligned}
$$

What is the source of the mistake? (show and explain how they may have found this solution).

Explain how you would respond to these comments and clear up confusion during class.

\section{APPENDIX B}

Table 1. Framework for characterizing pre-service teachers' level of KCS (Adapted from Ebert, 1994)

\begin{tabular}{ll}
\hline Level & Key features \\
\cline { 2 - 3 } & Knowledge of functions content and students
\end{tabular}

Level 0 - Have difficulties in identifying students' emerging errors, difficulties and misconceptions about the function concept

- Find difficulties to diagnose students' emerging errors and misconceptions about the function concept

- When choosing examples, not able to pay attention to aspects of the examples that will excite, motivate and interest the students

- Not able to mind the level of difficulty of the tasks that you assign to students

- Not able to pay attention to students' use of mathematical language and symbols related to functions

Level 1 - Identify students' emerging errors, difficulties and misconceptions about the function concept

- When choosing examples partially pay attention to aspects of the examples that will excite, motivate and interest the students

- Partially mindful of the level of difficulty of the tasks that you assign to students

- Partially able to pay attention to students' use of mathematical language and symbols related to functions

Level 2 - Able to easily identify and diagnose students' emerging errors, difficulties and misconceptions about the function concept

- Able to easily diagnose students' emerging errors and misconceptions about the function concept

- Able pay attention to aspects of the examples that will excite, motivate and interest the students when choosing examples during lesson preparation

- Able to be mindful of the level of difficulty of the tasks that you assign to students

- Pay attention to students' use of mathematical language and symbols related to functions

\section{http://www.ejmste.com}

